\title{
PENINGKATAN KETERAMPILAN MEMBERI UMPAN BALIK GURU PENDIDIKAN JASMANI OLAHRAGA DAN KESEHATAN (STUDI PADA GURU PENDIDIKAN JASMANI OLAHRAGA DAN KESEHATAN)
}

\author{
Sucahyo Mas an Al wahid ${ }^{1}$ \\ Hegen Dadang Prayoga ${ }^{2}$ \\ Universitas Borneo Tarakan \\ Universitas Islam Kalimantan Muhammad Arsyad Al Banjari Banjarmasin \\ E-mail: cahyowahid@gmail.com/ No. HP 085247997444
}

\begin{abstract}
ABSTRAK
Penelitian ini bertujuan untuk mengetahui tindakan pendampingan yang mampu meningkatkan keterampilan mengajar terutama pada aspek memberi umpan balik guru pendidikan jasmani olahraga dan kesehatan Sekolah Dasar Negeri di Kecamatan Taman kabupaten sidoarjo setelah diberikan pendampingan. Jenis penelitian ini merupakan penelitian tindakan (action reseach).Tindakan dalam penelitian ini yaitu, 1.Pemberian tayangan video keterampilan memberi umpan balik pada data primer, 2.Pendampingan perekaman dan diskusi hasil dilapangan, 3.Refleksi. Subjek dari penelitian ini ada 4 Guru Pendidikan Jasmani Olahraga dan Kesehatan SDN di Kecamatan Taman Kabupaten Sidoarjo. Data hasil dari penelitian yang diperoleh dari nilai keterampilan memberi umpan balik pada 4 guru pendidikan jasmani olahraga dan kesehatan yaitu: (1) SDN Sepanjang I sebelumnya mendapatkan nilai 2 menjadi 5, (2) SDN Ketegan I sebelumnya mendapatkan nilai 2 menjadi 5, (3) SDN Trosobo I sebelumnya mendapatkan nilai 0 menjadi 2, (4) SDN Kramat Jegu II sebelumnya mendapatkan nilai 0 menjadi 2. Rata- rata pre-test 1 dan rata-rata post-test 3.5. Berdasarkan perhitungan statistik diketahui bahwa nilai $\mathrm{T}_{\text {hitung }} 8.70>\mathrm{T}_{\text {tabel }} 2.35$ sehingga dapat disumpulkan bahwa terdapat perbedaan signifikan antara pre-test dan post-test,dimana nilai pre-test lebih rendah dibandingkan dengan nilai post-test. Kesimpulan dalam penelitian ini setelah dilakukan tindakan pendampingan melalui data primer yaitu pemberian tayangan video pembelajaran, diskusi penilaian angket guru terutama dalam aspek keterampilan mengajar memberi umpan balik guru pendidikan jasmani olahraga dan kesehatan serta melakukan perekaman dan refleksi.Dapat meningkatkan keterampilan mengajar guru pendidikan jasmani olahraga dan kesehatan.
\end{abstract}

Kata Kunci: Memberi Umpan Balik; Guru; Tindakan Pendampingan.

\begin{abstract}
This study aims to determine the accompaniment measures that are able to improve teaching skills, especially in the aspect of giving feedback on physical education teachers at the Elementary School in the regency district of Sidoarjo after being given assistance. The type of this research is action research. Actions in this study are, 1. Providing video shows skills to provide feedback on primary data, 2. Record keeping and discussion of results in the field, 3. Reflection. The subjects of this study were four Physical Education Teachers in Elementary Schools in the Regency District of Sidoarjo. Data from the research results obtained from the value of the skills of giving feedback to 4 sports and health physical education teachers, namely: (1) Sepanjang I elementary school previously obtained a value of 2 to 5, (2) Ketegan I elementary school previously got a value of 2 to 5, (3) Trosobo I Elementary School previously received a value of 0 to 2, (4) Kramat Jegu II Elementary School previously obtained a value of 0 to 2. Average pre-test 1 and post-test average 3.5. Based on statistical calculations it is known that the value of T_hitung8.70>T_table 2.35 so that it can be concluded that there are significant differences between the pre-test and post-test, where the pre-test value is lower than the post-test value. Conclusions in this study after the act of assistance through primary data, namely the provision of video learning shows, discussion of assessment of teacher questionnaires, especially in aspects of teaching skills provide feedback on physical education teachers as well as recording and reflection.
\end{abstract}

Keywords: Giving Feedback; Teacher; Assistance Actions. 


\section{PENDAHULUAN}

Pendahuluan harus berisi (secara berurutan) latar belakang umum, kajian literatur terdahulu (state of the art) sebagai dasar pernyataan kebaruan ilmiah dari artikel, pernyataan kebaruan ilmiah, dan permasalahan penelitian atau hipotesis. Di bagian akhir pendahuluan harus dituliskan tujuan kajian artikel tersebut. Di dalam format artikel ilmiah tidak diperkenankan adanya tinjauan pustaka sebagaimana di laporan penelitian, tetapi diwujudkan dalam bentuk kajian literatur terdahulu (state of the art) untuk menunjukkan kebaruan ilmiah artikel tersebut.

Pendahuluan artikel umumnya memuat rasional atau alasan logis terkait pemilihan tema, judul, atau variabel yang diangkat menjadi isu penelitian. Dalam pendahuluan, isu-isu menarik yang menjadi dasar pemikiran bagi penelitian dibahas secara mendalam didukung dengan kajian teoretis, temuan empiris (hasil penelitian terdahulu), maupun fakta lapangan. Penting untuk menunjukkan kesenjangan hasil penelitian (research gap), maupun kesenjangan teoritis (theory gap) yang menjadi dasar untuk mengemukakan isu untuk diteliti.

\section{METODE}

Metode penelitian yang digunakan adalah metode Penelitian Tindakan (Action Research).Pelaksanaan penelitian melibatkan rekan sebagai kolaborator dan guru kelas, kemudian peneliti sebagai pelaksana tindakan. Dengan desain penelitian Kemmis dan taggart yang meliputi: 1) perencanaan, 2) pelaksanaan, 3) pengamatan, dan 4) refleksi.

Berikut model Stephen Kemmis dan Mc Taggart yang mana menggunakan sistem spiral cyclical refleksi diri. Seperti pada gambar berikut :

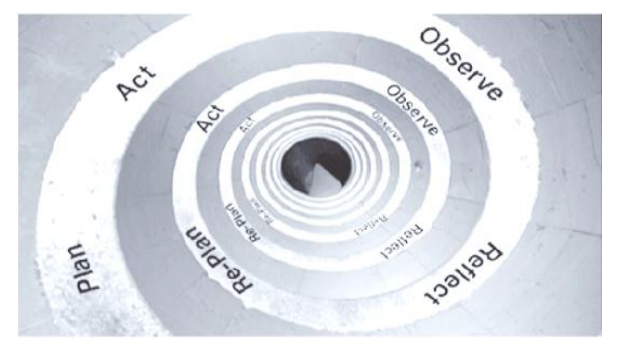

Gambar 1.S piral cyclical

Sumber: Stephen Kemmis, Robin dan Mc Taggart, The Action Research Planner Doing Critical Participatory Action Research. (Springer, 2014:19).

\section{HASIL DAN PEMBAHASAN}

Di bawah ini adalah grafik hasil peningkatan keterampilan mengajar pembelajaran keseluruhan guru dan keterampilan mengajar pembelajaran aspek memberi umpan balik guru yaitu sebagai berikut :

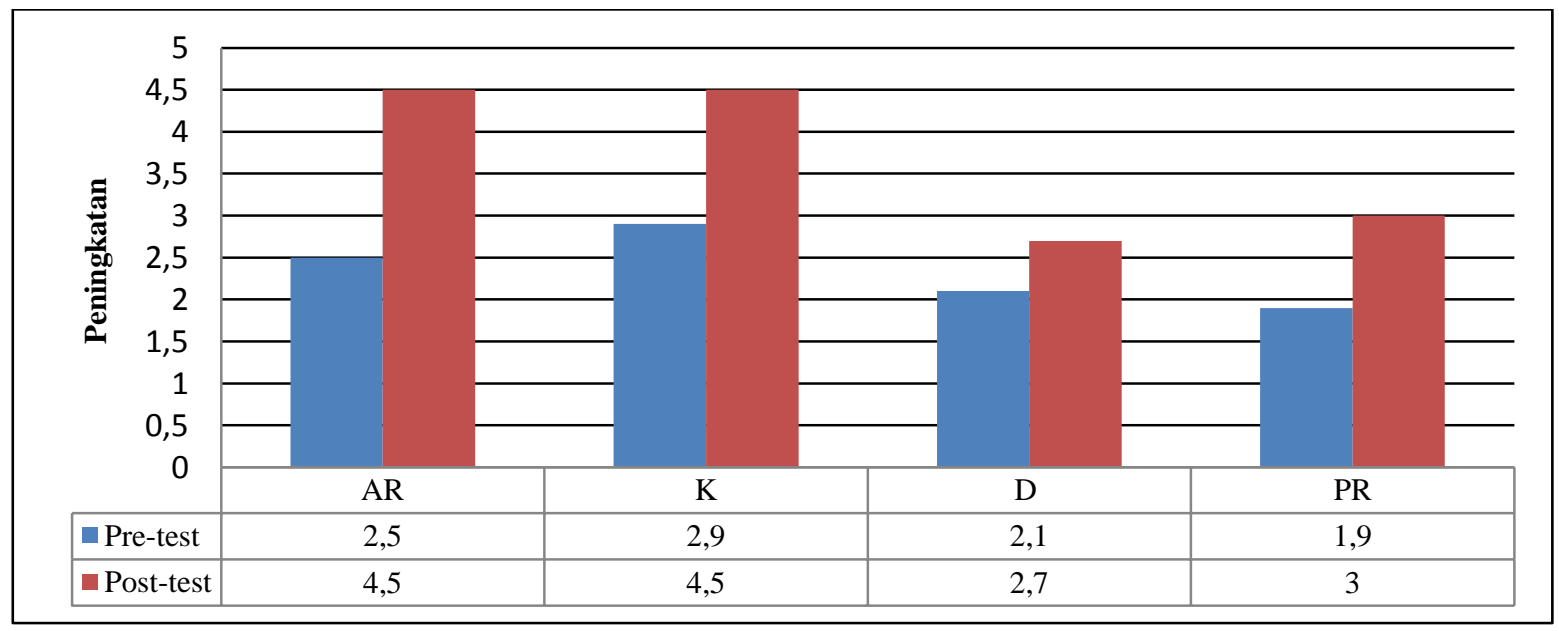


Grafik 4.1. Hasil Peningkatan Keseluruhan Keterampilan Mengajar Guru Pendidikan Jasmani olahraga dan Kesehatan.

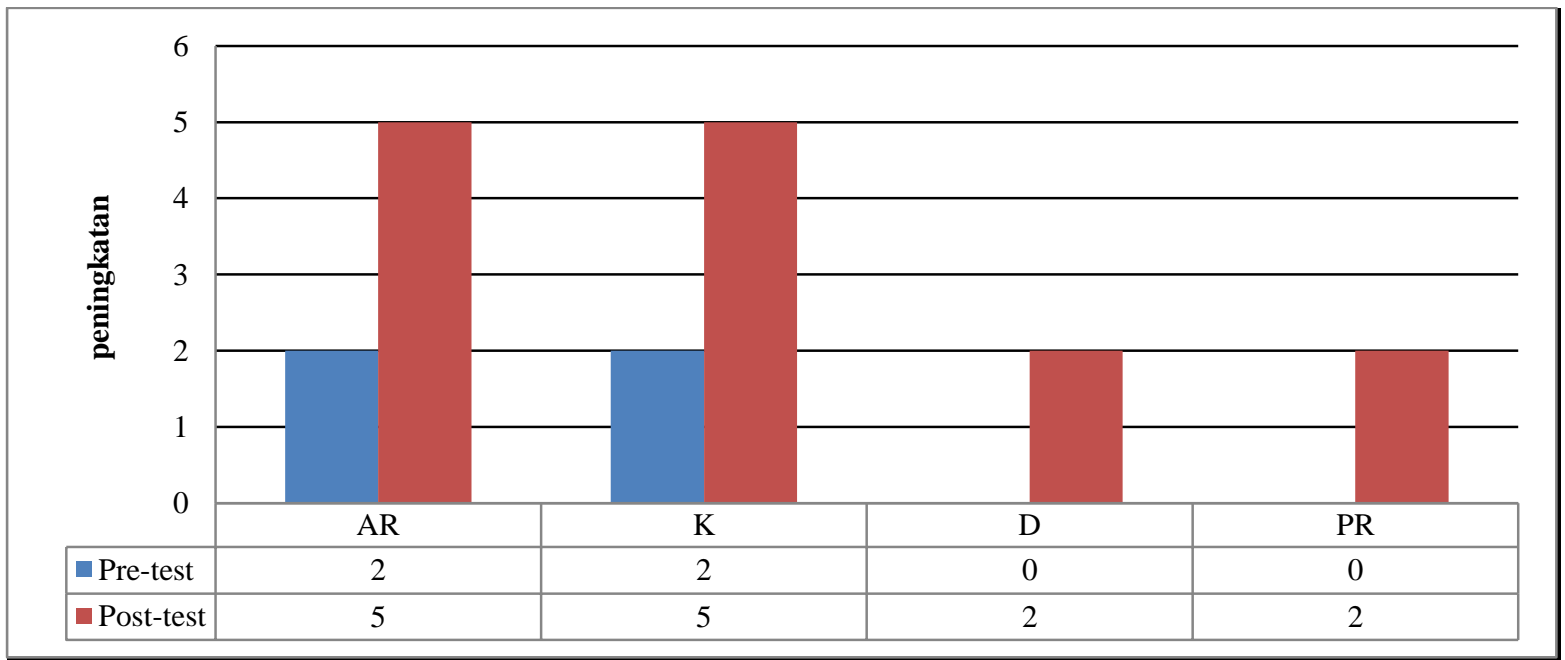

Grafik 4.2. Hasil Peningkatan Keterampilan Memberi Umpan Balik Pembelajaran Guru Pendidikan Jasmani olahraga dan Kesehatan.

Berdasarkan grafik di atas dapat dilihat bahwa semua guru dalam keterampilan mengajar pembelajaran mengalami peningkatan terutama dalam memberi umpan balik pembelajaran dapat juga dikatakan signifikan.

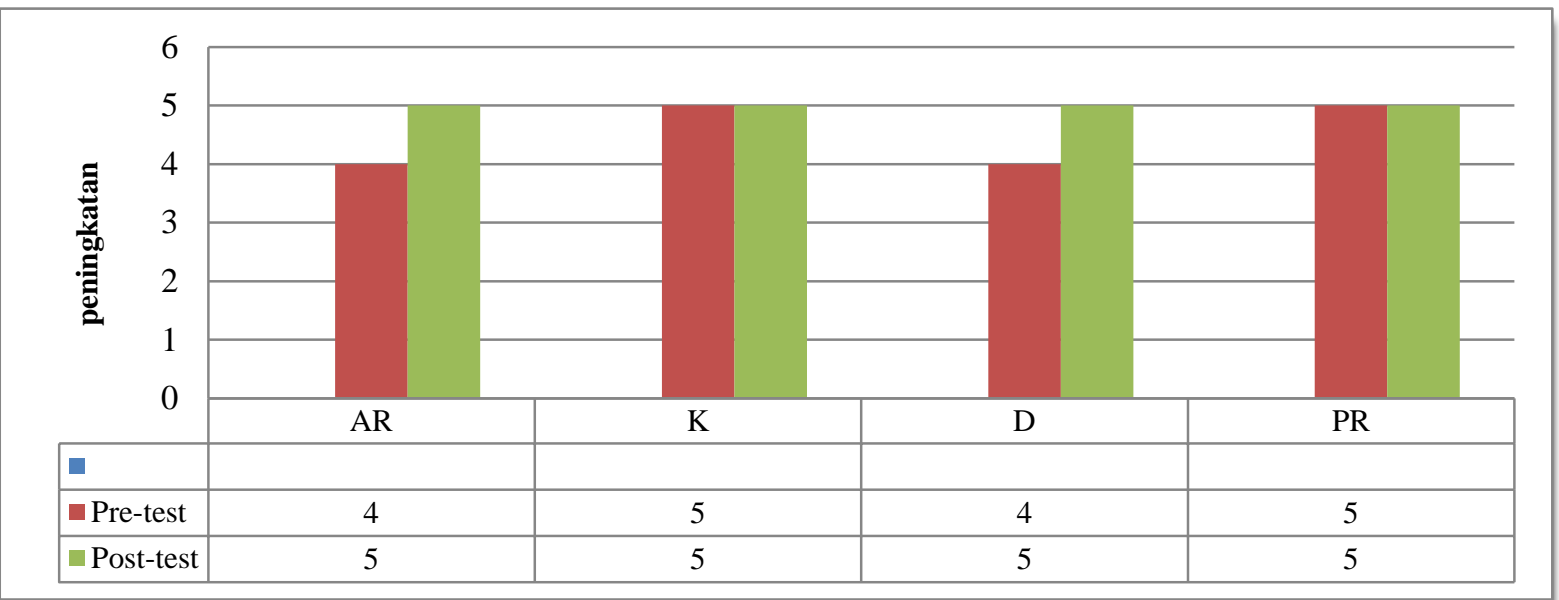

Grafik 4.3. Efektivitas Pembelajaran Berdasarkan FCE

Keterangan :Nilai 4 = Baik, Nilai 5 = Baik Sekali

Berdasarkan grafik di atas dapat disimpulkan bahwa tidak ada perbedaan nilai efektivitas pembelajaran dari pretest dan post-test.Akan tetapi terdapat perbedaan nilai akhir menurut instrument FCE adalah 4, 5, 4, 5 Pretest dan 5, 5, 5, 5 post-test.Hasil rekap penelitian di atas merupakan keseluruhan rangkaian proses Pembelajaran Pendidikan Jasmani Olahraga dan Kesehatan SDN di Kecamatan Taman Kabupaten Sidoarjo.

Semua guru dari empat sekolah tersebut telah berpedoman pada konsep tujuan pendidikan jasmani sesuai dengan Suranto (2004) memendefinisikan pendidikan jasmani menguntungkan dalam penyesuaian dari belajar gerak, neuro-muscular, sosial, kebudayaan, baik emosional dan etika sebagai akibat yang timbul melalui pilihannya yang baik melalui aktifitas fisik yang menggunakan sebagian besar otot tubuh. Selain itu dapat 
mengembangkan afektif atau sikap menurut Popham (1995), ranah afektif menentukan keberhasilan belajar seseorang.

Pada diskusi hasil penelitian ini, peneliti akan mendeskripsikan keterampilan mengajar guru kecamatan taman sesuai dengan kaji tindak lapangan, proses dan hasil keterampilan mengajar guru pendidikan jasmani olahraga dan kesehatan terutama pada aspek memberi umpan balik pembelajaran serta Peraturan Pemerintah Republik Indonesia Nomer 14 tahun 2005 tentang Guru dan Dosen pasal 1 ayat 1. Pembahasan ini bertujuan untuk mengutip tentang persiapan mengajar sarana dan prasarana serta perangkat pengajaran, penyesuaian pemberian materi dan indikator pembelajaran, penguasaan guru kepada peserta didik pada saat mengajar dan adanya pemberian umpan balik untuk penguatan hasil belajar.

Peneliti membahas tentang keterampilan mengajar bapak AR dalam membelajarkan peserta didiknya pada SDN Sepanjang I yaitu pada tahap persiapan sarana dan prasarana serta perangkat pembelajaran telah disiapkan oleh bapak AR sebelum pembelajaran di mulai berarti bapak AR telah siap untuk melaksanakan proses belajar mengajar. Pemberian indikator pembelajaran pada materi atletik lompat tinggi oleh bapak AR mendapatkan partisipasi positif karena memberikan contoh sesuai dengan kemampuan peserta didik dan mengulangi penjelasan apabila belum dimengerti, Tohirin (2005: 152) menyatakan, tuntutan masyarakat khususnya peserta didik dari guru dalam aspek etis, intelektual dan sosial lebih tinggi daripada yang dituntut dari orang dewasa lainnya.

Keterampilan mengajar bapak K dalam membelajarkan peserta didik dengan menerima inisiatif peserta didik yang disampaikan melalui pertanyaan, bahasan, atau saran-saran (Surya, 1997: 144-145). Pada proses pembelajaran bapak K tepatnya pada SDN Ketegan I selalu mencegah agar perilaku peserta didik yang salah tidak berketerusan dan mengarahkan suatu tindakan dengan sikap disiplin secara tepat, dengan demikian bapak $\mathrm{K}$ mengamati keseluruhan peserta didik agar melaksanakan pembelajaran dengan indikator yang diberikan semua dapat melakukan dengan sikap yang bijaksana (dengan cara non verbal, melalui isyarat, pesan-pesan, kedekatan, kontak mata dan memberikan waktu khusus dalam melakukan tugas gerak yang diberikan).

Setelah itu, peneliti mendapatkan catatan khusus untuk ibu D yaitu persiapan pembelajaran pada perangkat pembelajaran yang ternilai kurang serta lapangan untuk melaksanakan proses belajar mengajar tidak memadai pada SDN Trosobo I sesuai dengan pernyataan Setyorini (2009), sarana prasarana pada bangunan sekolah yang rusak mempengaruhi kualitas pendidikan peserta didiknya karena secara psikologis anak tidak nyaman belajar pada bangunan yang hampir roboh. Proses belajar mengajar oleh ibu D hanya memberikan umpan balik verbal singkat secara berulang-ulang, mulai dari pembukaan hingga menutup pembelajaran. Hal itu dikarenakan ibu D hanya ingin peserta didik lebih pada sikap afektif dibandingkan dengan psikomotor dan kognitif.

Serta terakhir peneliti membahas tentang keterampilan mengajar yang peneliti temukan oleh ibu PR pada instansi sekolah SDN Kramat Jegu II, perangkat pembelajaran atau kesiapan rencana pengajaran belum peneliti dapatkan dalam bentuk fisik atau karena masih dalam bentuk file, berdasarkan peraturan PERMENDIKNAS Nomer 41 Tahun 2007 tentang standar proses pembelajaran untuk satuan pendidikan dasar dan menengah dapat mencakup perencanaan proses pembelajaran, pelaksanaan pembelajaran, penilaian hasil belajar dan pengawasan proses pembelajaran (pemantauan, supervisi, evaluasi). Indikator terlaksana oleh ibu PR karena pada menutup pembelajaran ibu PR memberikan tugas mengerjakan LKS akan tetapi tujuan dari psikomotor atau aktifitas fisik untuk penilaian masih kurang sedangkan afektif terpenuhi dengan adanya pembagian kelompok untuk melakukan suatu gerakan yang berbeda.

\section{PENUTUP}

Kesimpulan dalam penelitian ini setelah dilakukan tindakan pendampingan melalui data primer yaitu pemberian tayangan video pembelajaran, diskusi penilaian angket guru terutama dalam aspek keterampilan mengajar, memberi umpan balik guru pendidikan jasmani olahraga dan kesehatan serta melakukan perekaman dan refleksi. Dapat meningkatkan keterampilan mengajar guru pendidikan jasmani olahraga dan kesehatan.

Saran dalam penelitian ini diperlukan keterbukaan referensi dan pengalaman antara guru dan peneliti dalam hal keterampilan mengajar.

\section{REFERENSI}

Buku 1 Penulis

Hamalik, Oemar. (2003).Pendidikan Guru Berdasarkan Pendekatan Kompetensi. Jakarta: Bumi Aksara.

Buku 2 Penulis

Maksum, Ali. (2012). Metodelogi Penelitian dalam Olahraga.Penerbit: Unesa University Press.

Buku 3 Penulis

Mahardika, I. Made. S. (2010). Pengantar Evaluasi Pengajaran. Penerbit: Unesa University Press2010 ix, 301 hal., Illus, 28. 


\section{Laporan akhir dana hibah}

Suroto dan Khory, D.F. (2013).Peningkatan Keterampilan Mengelola Pembelajaran Aktif melalui Pendekatan Lesson Study (Studi pada Guru Penjasorkes SDN di Kecamatan Taman Kabupaten Sidoarjo). (laporan akhir) Surabaya : LPPM Unesa.

Artikel Jurnal / Ensiklopedi

Afshari, Mojgan., Bakar, A. K., Luan, W. S., Samah, B. A., Fooi, F. S. (2009). Factors Affecting teachers' Use of Information and Communication Technology. January 2009. Vol.2, No.1

Hattie,J, and Timperley, H. (2007). Review of Educational Research.University of Auckland March 2007, Vol. 77, No. 1, pp. 81-112.

Handler, Beth.(2010). Teacher as Curriculum Leader.University of Wisconsin-Madison, Wisconsin, U.S.A. Volume 3, Number 3, Winter.

Kemmis, Stephen, in Geoffrey E. Mills. Action Research: A Guide For The Teacher Researcher (New Jersey: Prentice-Hall, 2010)

Khatri, R. (2013). "Feedback, Student Collaboration, and Teacher."Support ESL Instructur at the University of Regina, Canada Volume 2, Nomer 2.

Kilic Abdurrahman. (2010). Learner-Centered Micro Teaching in Teacher Education. Assoc. Prof., Duzce University, Education Science,Turkey. International Journal of Insturction. Vol, 3.No.1.

Kimm and Swanwick.(2009). Clinical Teaching Made Easy.British Journal of HospitalMedicine, March 2009, Vol 70, No 3. Vol. 6 ,

Kiser, K. (2002). Is Blended Best? E-Learning, 3(6), 10. Journal Of Information Technology Education.

Marold, K., \& Haga, W. (2003).The Emerging Profile of the on-line Learner: Relating Course. Performance with Presents, GPA, and other Measures of Achievement. Proccedingsof the Information Resource Management Association (IRMA) Conference (pp. 248-251). Journal Of Information Technology Education. Vol. 6,.

Milis, Iwona. (2007). Importance of face to face Interaction.Victoria University, Melbourne, Australia. Journal Of Information Technology Education. Vol. 6,.

Sudijandoko, Andun. (2010). Pembelajaran Pendidikan Jasmani yang Efektif dan Berkualitas. Jurnal Pendidikan Jasmani Indonesia Volume 7, Nomor 1,.

Vishwanath Bite and Madhuri Bite. (2012). The Criterion : Managerial Skill for Teacher. An International Journal in English. Vol. III, Issue III.

Yen, Tan Sin and Halili, S. H. (2015).Effective Teaching of Higher-Order Thinking (HOT) in Education. The Online Journal of Distance Education and e-Learning. Vol. 3, Issue 2. 